\title{
A method for increasing the surface area of perovskite-type oxides
}

\author{
S BANERJEE and V R CHOUDHARY* \\ Chemical Engineering Division, National Chemical Laboratory, \\ Pune 411 008, India \\ e-mail: vrc@che.ncl.res.in; vrc@ems.ncl.res.in
}

MS received 13 March 2000; revised 25 April 2000

\begin{abstract}
A method based on hydrothermal treatments is described for increasing the surface area of sintered $\mathrm{ABO}_{3}$-type perovskite oxides. Influence of hydrothermal treatments, such as water treatment at $125-300^{\circ} \mathrm{C}$ under autogeneous pressure and steam treatment at $350-800^{\circ} \mathrm{C}$, to low surface area (or sintered) $\mathrm{LaCoO}_{3}$ and $\mathrm{LaMnO}_{3}$ perovskite oxides on their surface properties (viz. surface area, crystal size and morphology and surface $\mathrm{La} /(\mathrm{Co}$ or $\mathrm{Mn}$ ) ratio) and also catalytic activity in complete combustion of methane at different temperatures $\left(450-600^{\circ} \mathrm{C}\right)$ has been thoroughly investigated. The hydrothermal treatments result in the activation of the perovskite oxides by increasing their surface area very markedly.
\end{abstract}

Keywords. $\mathrm{ABO}_{3}$-type perovskite oxides; $\mathrm{LaCoO}_{3} ; \quad \mathrm{LaMnO}_{3} ;$ hydrothermal treatment; catalytic combustion of methane.

\section{Introduction}

$\mathrm{ABO}_{3}$-type perovskite oxides $(\mathrm{A}=$ rare earth element with or without its partial substitution by alkaline earth element, and $\mathrm{B}=$ transition element such as $\mathrm{Co}, \mathrm{Mn}, \mathrm{Ni}, \mathrm{Fe}$, etc., with or without its partial substitution by other transition elements) have high potential for their use as catalysts in a number of catalytic reactions ${ }^{1-5}$. The classical ceramic solid-solid reaction and co-precipitation methods, commonly used for the synthesis of perovskite-type oxide, involve high reaction temperature $\left(>900^{\circ} \mathrm{C}\right)$ and hence yield perovskite-type oxides with a low surface area $\left(<2 \mathrm{~m}^{2} \mathrm{~g}^{-1}\right)$ due to their sintering ${ }^{1}$. The perovskite-type oxides are also deactivated due to sintering or crystal growth during their continuous use in high temperature processes. The catalytic performance of the perovskite-type oxides is well-known to depend on their specific surface area ${ }^{1,2,6}$, and hence it is of great practical interest to activate low surface area perovskite oxides, which are prepared by the high temperature synthesis methods and/or sintered during their use, by some means. In our very recent communication ${ }^{8}$, we have reported a possibility of activating sintered or low surface area $\mathrm{LaCoO}_{3}$ and $\mathrm{LaMnO}_{3}$ perovskite-type oxides by their hydrothermal treatment with water (under autogeneous pressure) or steam (at atmospheric pressure). The present work was undertaken with the objective of thoroughly investigating the activation of the low surface area perovskite oxides by the hydrothermal treatments for the complete combustion of methane.

*For correspondence 


\section{Experimental methods}

The $\mathrm{LaCoO}_{3}$ (surface area $\left.\mathrm{SA}=0.9 \mathrm{~m}^{2} \mathrm{~g}^{-1}\right)$ and $\mathrm{LaMnO}_{3}\left(\mathrm{SA}=1.7 \mathrm{~m}^{2} \mathrm{~g}^{-1}\right)$ perovskitetype oxides were prepared by carbonate coprecipitation method involving calcination at $925^{\circ} \mathrm{C}$. The hydrothermal treatment to the perovskite-type oxide with water under autogeneous pressure was carried out in a closed stainless steel bomb, using $1.6 \mathrm{ml}$ water per gram of perovskite-type oxide, at different temperatures for $4 \mathrm{~h}$. The hydrothermal treatment to the $\mathrm{LaCoO}_{3}$ with steam at atmospheric pressure was carried out in a conventional quartz reactor by passing a mixture of steam and $\mathrm{N}_{2}(60$ mole $\%$ steam) at a space velocity of $5100 \mathrm{~cm}^{3} \mathrm{~g}^{-1} \mathrm{~h}^{-1}$. After the hydrothermal treatment, the perovskite-type oxides were calcined at $600^{\circ} \mathrm{C}$ for $1 \mathrm{~h}$.

The perovskite-type oxides were characterized by XRD using a $\mathrm{CuK} \alpha$ radiation, by XPS for determining the surface $\mathrm{La} /(\mathrm{Co}$ or $\mathrm{Mn})$ atomic ratio, by Scanning Electron Microscope for their crystal size and morphology, and also for their surface area using a Monosorb Surface Area Analyzer (Quantachrome Corp., USA).

The catalytic activity of the perovskite-type oxides in a complete combustion of methane was measured by passing continuously a methane ( $2.5 \mathrm{~mole} \%)$-air mixture at a space velocity of $51,000 \mathrm{~cm}^{3} \mathrm{~g}^{-1} \mathrm{~h}^{-1}$ (measured at $0^{\circ} \mathrm{C}$ and atmospheric pressure) over a $0.1 \mathrm{~g}$ catalyst diluted uniformly with $0.4 \mathrm{~g}$ inert solid particles in a quartz reactor at different temperatures and analyzing the reaction products by an on-line gas chromatograph as described earlier ${ }^{7}$.

\section{Results and discussion}

The scanning electron micrographs of $\mathrm{LaCoO}_{3}$ and $\mathrm{LaMnO}_{3}$ perovskite oxides with or without hydrothermal treatment are shown in figures 1 and 2. The XRD spectra of $\mathrm{LaCoO}_{3}$ and $\mathrm{LaMnO}_{3}$ perovskite-type oxides with or without hydrothermal treatment are shown in figures 3 and 4 . Results showing the influence of temperature on the conversion of methane in its complete combustion over hydrothermally treated $\mathrm{LaCoO}_{3}$ and $\mathrm{LaMnO}_{3}$ perovskite oxides are presented in figures 5-7. The $\mathrm{LaCoO}_{3}$ and $\mathrm{LaMnO}_{3}$ perovskites with or without hydrothermal treatment are compared for their surface area, crystal size and surface $\mathrm{La} /(\mathrm{Co}$ or $\mathrm{Mn})$ atomic ratio in tables 1 and 2.

The following observations are made from the results (figures 1-5 and tables 1-2) of the water treatment to $\mathrm{LaCoO}_{3}$ and $\mathrm{LaMnO}_{3}$ perovskites and steam treatment to $\mathrm{LaCoO}_{3}$ perovskite oxide:

- Both the water and steam treatments (at different temperatures) have no significant effect on the structure of perovskite oxides.

- The hydrothermal treatments result in a very significant increase in surface area for $\mathrm{LaCoO}_{3}$ perovskite oxide, but for $\mathrm{LaMnO}_{3}$ perovskite, the increase in surface area is relatively less.

- The steam treatment of $\mathrm{LaCoO}_{3}$ perovskite results in a small increase in its surface area.

- In case of $\mathrm{LaCoO}_{3}$, there is a very significant change in the crystal size and morphology due to the hydrothermal treatment (figure 1), depending upon its severity. However, in case of $\mathrm{LaMnO}_{3}$, the observed changes in the crystal size and morphology after the hydrothermal treatment are relatively very small (figure 2). 

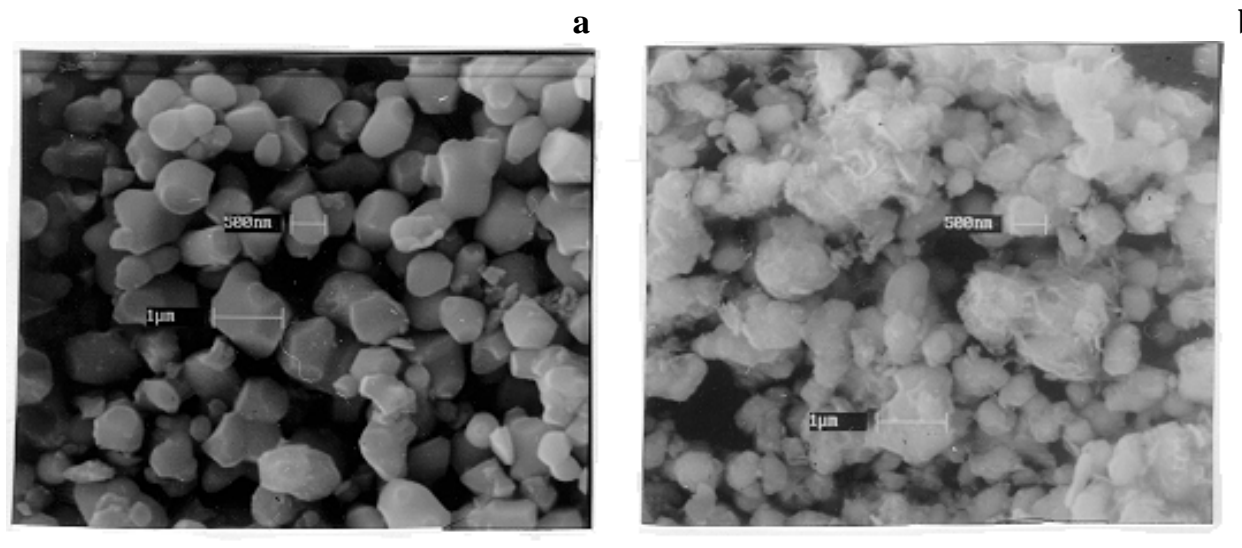

c
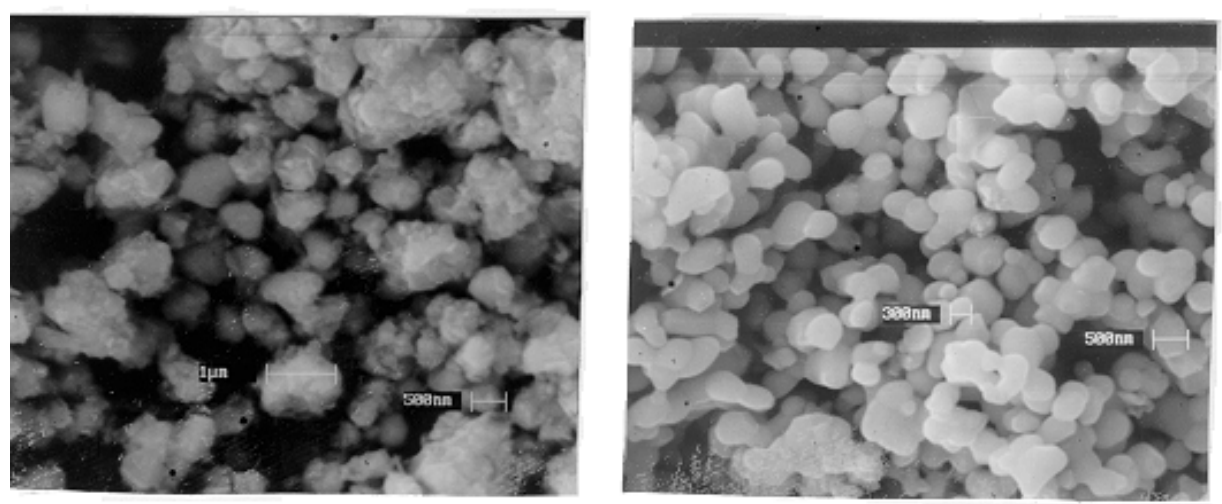

Figure 1. Scanning electron micrograph of $\mathrm{LaCoO}_{3}$ without water treatment (a), treated with water at $175^{\circ} \mathrm{C}(\mathbf{b})$, at $225^{\circ} \mathrm{C}(\mathbf{c})$, treated with steam at $800^{\circ} \mathrm{C}(\mathbf{d})$.

Table 1. Surface area, crystal size and surface $\mathrm{La} /(\mathrm{Co}$ or $\mathrm{Mn})$ ratio of $\mathrm{LaCoO}_{3}$ and $\mathrm{LaMnO}_{3}$ perovskite oxides treated with water under autogeneous pressure.

\begin{tabular}{lcccc}
\hline $\begin{array}{l}\text { Perovskite } \\
\text { oxide }\end{array}$ & $\begin{array}{c}\text { Water treatment } \\
\text { temperature }\left({ }^{\circ} \mathrm{C}\right)\end{array}$ & $\begin{array}{c}\text { Surface area } \\
\left(\mathrm{m}^{2} \mathrm{~g}^{-1}\right)\end{array}$ & $\begin{array}{c}\text { Crystal size } \\
(\mu \mathrm{m})\end{array}$ & $\begin{array}{c}\text { Surface La/(Co } \\
\text { or Mn) ratio }\end{array}$ \\
\hline $\mathrm{LaCoO}_{3}$ & $\begin{array}{c}\text { Without treatment } \\
125\end{array}$ & 0.9 & $1 \cdot 1$ & 0.98 \\
& 175 & 7.8 & - & - \\
& 225 & 14.3 & $0 \cdot 7$ & - \\
$\mathrm{LaMnO}_{3}$ & Without treatment & 16.0 & 0.6 & 1.30 \\
& 175 & 3.0 & 0.5 & 1.08 \\
& 225 & 3.9 & - & - \\
& 300 & 4.5 & 0.45 & 1.11 \\
\hline
\end{tabular}


$\mathbf{a}$
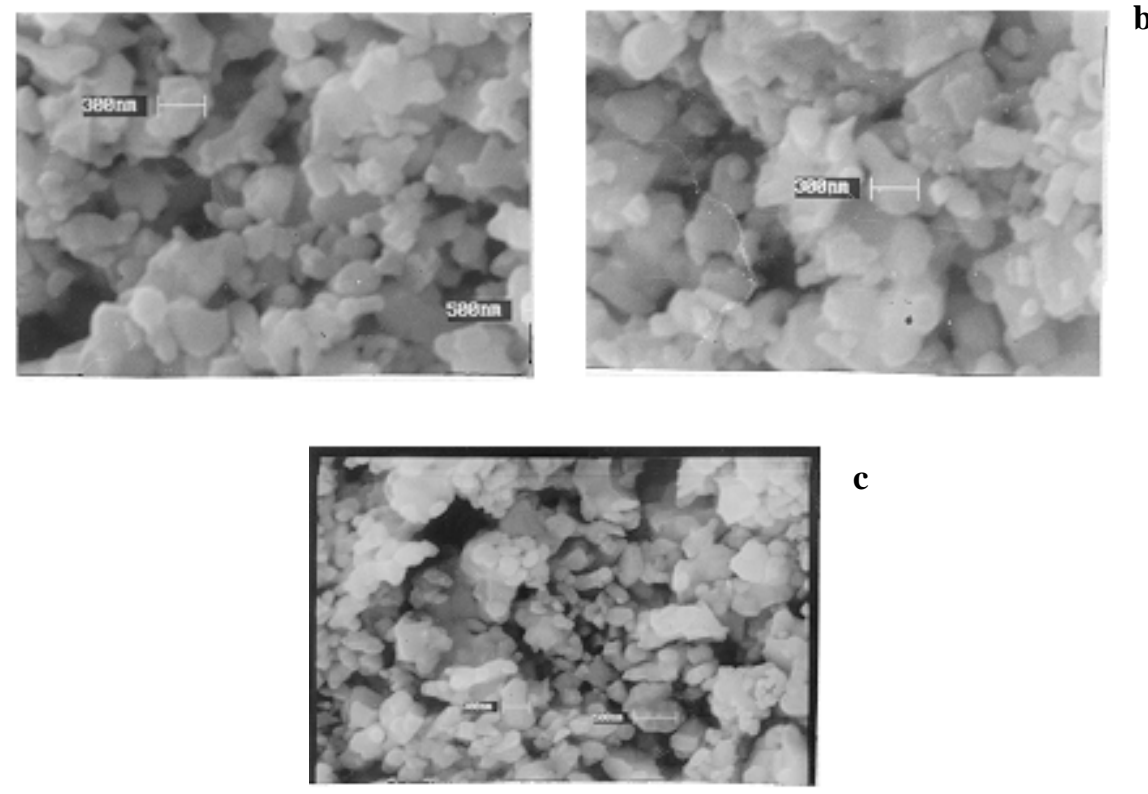

c

Figure 2. Scanning electron micrograph of $\mathrm{LaMnO}_{3}$ without water treatment (a), treated with water at $225^{\circ} \mathrm{C}(\mathbf{b})$ and at $300^{\circ} \mathrm{C}(\mathbf{c})$.

Table 2. Surface area, crystal size and surface $\mathrm{La} /(\mathrm{Co}$ or $\mathrm{Mn})$ ratio of $\mathrm{LaCoO}_{3}$ treated with steam at atmospheric pressure.

\begin{tabular}{lccc}
\hline $\begin{array}{l}\text { Steam treatment } \\
\text { temperature }\left({ }^{\circ} \mathrm{C}\right)\end{array}$ & $\begin{array}{c}\text { Surface area } \\
\left(\mathrm{m}^{2} \mathrm{~g}^{-1}\right)\end{array}$ & $\begin{array}{c}\text { Crystal size } \\
(\mu \mathrm{m})\end{array}$ & $\begin{array}{c}\text { Surface La/Co } \\
\text { ratio }\end{array}$ \\
\hline Without treatment & $0 \cdot 9$ & $1 \cdot 1$ & 0.98 \\
350 & $1 \cdot 4$ & - & - \\
500 & $1 \cdot 5$ & - & - \\
600 & $1 \cdot 7$ & - & - \\
700 & 1.9 & - & - \\
800 & $2 \cdot 3$ & $0 \cdot 4$ & 1.08 \\
\hline
\end{tabular}

- The surface $\mathrm{La} / \mathrm{Co}$ (or $\mathrm{Mn}$ ) ratio of the perovskite oxides is increased with increasing the severity (i.e. temperature) of the hydrothermal treatment.

- The methane combustion activity of all the water and steam treated catalysts is higher than that of the untreated one. As compared to $\mathrm{LaMnO}_{3}$, the increase in the catalytic activity of $\mathrm{LaCoO}_{3}$ due to the hydrothermal treatments is larger.

These observations clearly indicate a beneficial effect of the hydrothermal treatments and steam treatment to the perovskite-type oxides for their activation or reactivation. This approach may also be employed for activating other low surface area or sintered perovskite-type oxides. 


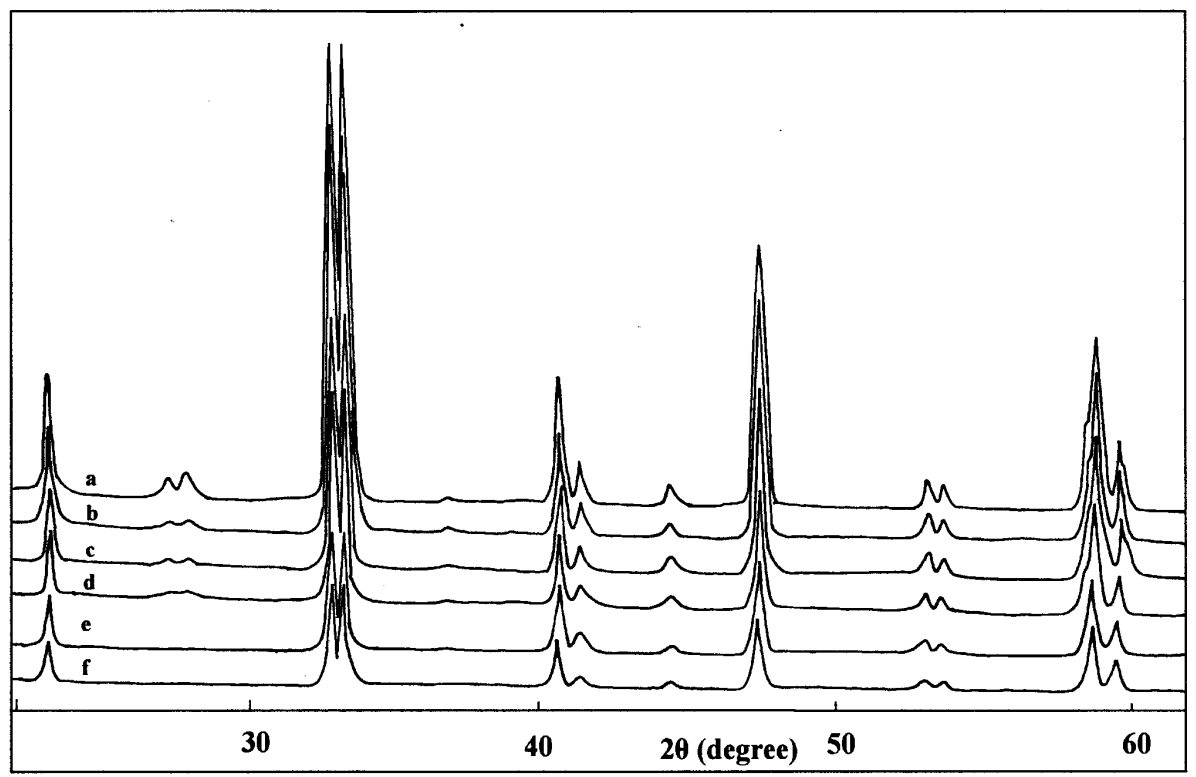

Figure 3. XRD spectra of $\mathrm{LaCoO}_{3}$ [without treatment (a), treated with water at $125^{\circ} \mathrm{C}(\mathbf{b}), 175^{\circ} \mathrm{C}(\mathbf{c}), 275^{\circ} \mathrm{C}(\mathbf{d})$, with steam at $350^{\circ} \mathrm{C}(\mathbf{e})$ and $\left.800^{\circ} \mathrm{C}(\mathbf{f})\right]$.

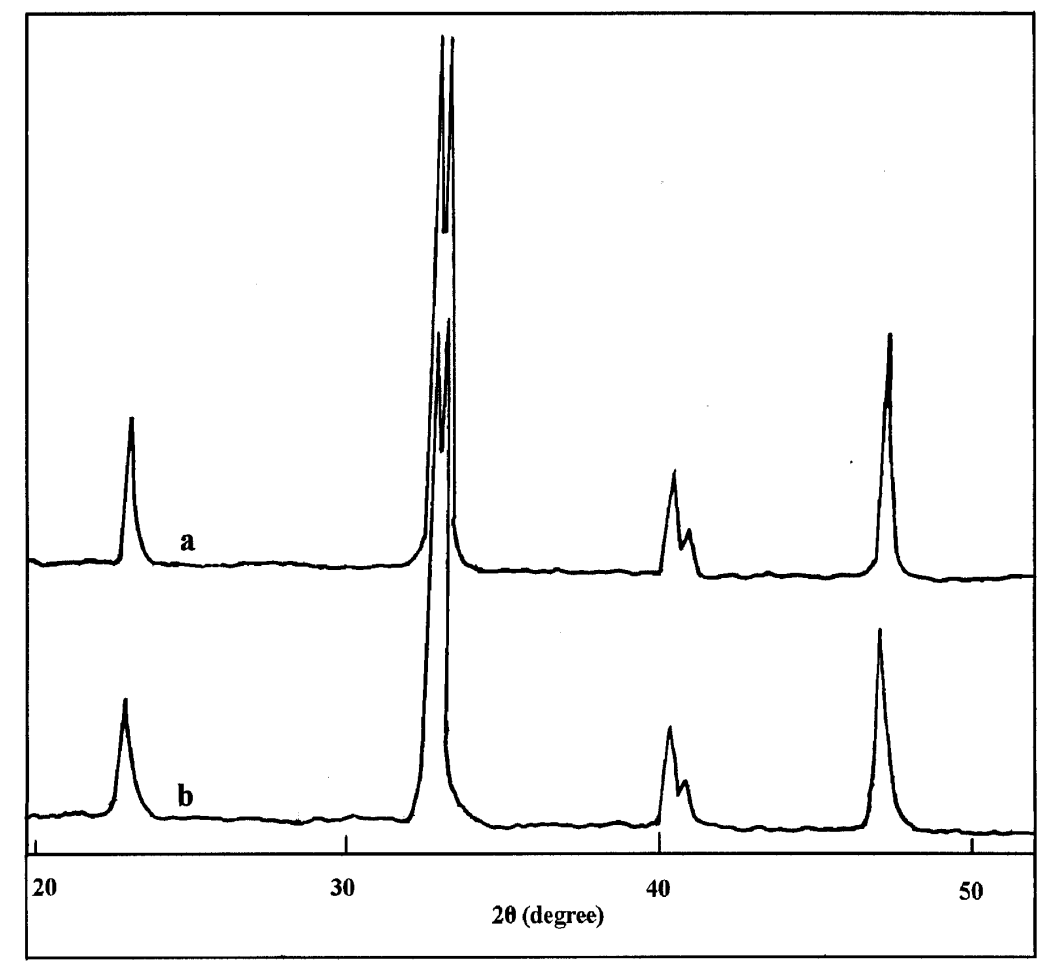

Figure 4. XRD spectra of $\mathrm{LaMnO}_{3}$ [without treatment (a), treated with water at $\left.225^{\circ} \mathrm{C}(\mathbf{b})\right]$. 


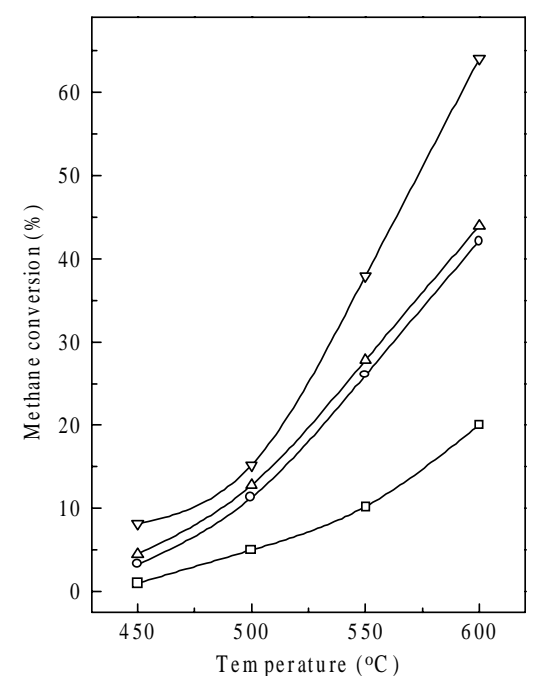

Figure 5. Effect of temperature on the conversion of methane in its complete combustion over $\mathrm{LaCoO}_{3}$ - treated with water at $125^{\circ} \mathrm{C}(\bigcirc), 175^{\circ} \mathrm{C}(\triangle), 225^{\circ} \mathrm{C}(\nabla)$ and without water treatment $(\square)$.

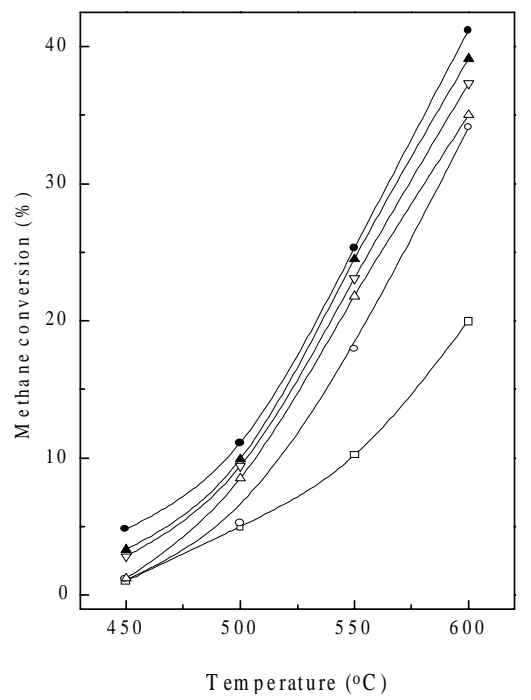

Figure 6. Effect of temperature on the conversion of methane in its complete combustion over $\mathrm{LaCoO}_{3}$ - treated with steam at $350^{\circ} \mathrm{C}(\mathrm{O}), 500^{\circ} \mathrm{C}(\triangle), 600^{\circ} \mathrm{C}(\nabla)$, $700^{\circ} \mathrm{C}(\mathbf{\Delta}), 800^{\circ} \mathrm{C}(\bullet)$ and without water treatment $(\square)$.

The increase in the surface area of the perovskite-type oxides and the observed decrease in the crystal size by the steam treatment at $350-800^{\circ} \mathrm{C}$ are expected because of the recrystallization during the high temperature hydrothermal treatment depending upon the steam treatment temperature. Whereas in the water treatment at autogeneous pressure 


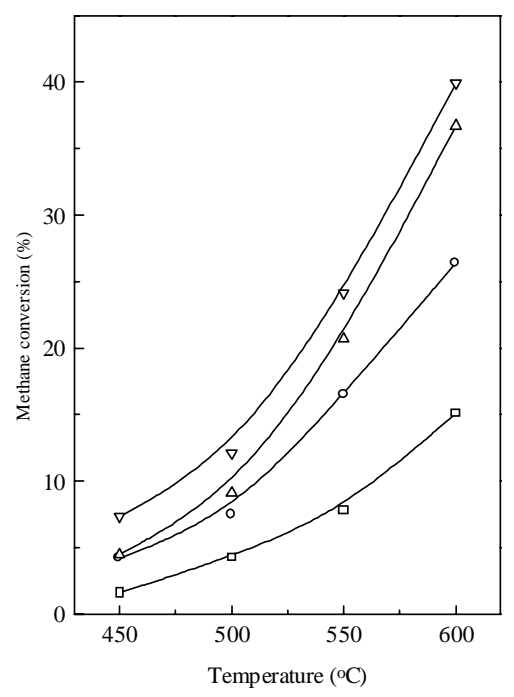

Figure 7. Effect of temperature on the conversion of methane in its complete combustion over $\mathrm{LaMnO}_{3}$ - treated with water at $175^{\circ} \mathrm{C}(\mathrm{O}), 225^{\circ} \mathrm{C}(\triangle), 300^{\circ} \mathrm{C}(\nabla)$ and without water treatment $(\square)$.

(at $125-300^{\circ} \mathrm{C}$ ), the perovskite-type oxides are expected to be hydrolyzed, at least partially, and recrystallized during the calcination at $600^{\circ} \mathrm{C}$, leading to a large increase in their surface area. The hydrolysis followed by the recrystallization may have caused a larger change in the surface area and crystal size in case of the water treatment. The observed increase in the surface $\mathrm{La} / \mathrm{Co}$ (or $\mathrm{Mn}$ ) ratio with increasing the severity of the hydrothermal treatment in both the water and steam treatment also indicate the recrystallization of the perovskite-type oxide causing redistribution of $\mathrm{La}$ and $\mathrm{Co}$ (or $\mathrm{Mn})$.

The methane combustion activity, when expressed per unit mass of the perovskitetype oxide catalyst, is increased due to the hydrothermal pretreatment. However, the catalytic activity, when expressed per unit surface is decreased appreciably, particularly due to water treatment and this is consistent with the increase in the surface $\mathrm{La} / \mathrm{Co}$ (or $\mathrm{Mn}$ ) ratio or with the decrease in the surface concentration of Co or Mn (which is responsible for the combustion activity of the catalyst).

\section{Conclusions}

Surface area and catalytic activity (in the methane combustion for methane emission control) of low surface area (or sintered) $\mathrm{LaCoO}_{3}$ and $\mathrm{LaMnO}_{3}$ perovskite type oxides can be increased markedly by hydrothermal treatment of the perovskites with water (under autogeneous pressure) or steam. In the hydrothermal treatments, there is little or no influence on the structure of the perovskite oxide, but its crystal size and surface $\mathrm{La} / \mathrm{Co}$ (or $\mathrm{Mn}$ ) ratio are changed significantly; the former is decreased and the later is increased with increasing the severity of hydrothermal treatment. 


\section{Acknowledgement}

S Banerjee is grateful to the Council of Scientific and Industrial Research, New Delhi, for a fellowship. We are also grateful to Dr Sainkar and Dr Mandale of the Sophisticated Instrumentation Laboratory, for the SEM and XPS of the samples.

\section{References}

1. Voorhoeve R J H, Johnson Jr D W, Remeika J P and Gallagher P K 1977 Science 195827

2. Tejuca L G, Fierro J L G and Tascon J M D 1989 Adv. Catal. 36237

3. Tejuca L G and Fierro J L G 1993 (eds) In Properties and applications of perovskite-type oxides (New York: Marcel Dekker)

4. Seiyama T 1992 Catal. Rev. Sci. Eng. 34281

5. McCarty J G and Wise H 1990 Catal. Today 8231

6. Yamazoe N and Teraoka Y 1990 Catal. Today 8175

7. Choudhary V R, Uphade B S, Pataskar S G and Keshavaraja A 1996 Angew. Chem. Int. Ed. Engl. 352393

8. Choudhary V R, Banerjee S and Uphade B S 2000 Appl. Catal. A197 L183 